\title{
Concepção de Jogos Educativos para Crianças Surdas Baseados na Educação Infantil Bilíngue: Um estudo de caso de avaliação da metodologia CAJEDUS
}

\author{
Ludmilla Fernandes Oliveira Galvão ${ }^{1}$, Laura Sánchez García ${ }^{1}$, Tanya Amara Felipe ${ }^{2}$
}

Programa de Pós-Graduação em Informática - Universidade Federal do Paraná (UFPR)

${ }^{2}$ Instituto Nacional de Educação de Surdos (INES)

\{ludmillagalvao1, sg.laura, tanyafelipe\}@gmail.com

\begin{abstract}
The Deaf community needs, since childhood, computational tools to support Bilingual Education, with Libras as the preferred language and written Portuguese as a second language. One way to assist teaching and learning processes is the use of educational games, which are often not accessible and disregard the learning objectives of Bilingual Education. In this context, the CAJEDUS methodology (Game Creation for the EDUcation of Deaf children) was built to support the process of designing educational games for Deaf children aged 4 and 5, based on the objectives of Bilingual Education. A case study was conducted with developers and its results led to improve the methodology.
\end{abstract}

Resumo. A comunidade Surda necessita, desde a infância, de ferramentas computacionais para o apoio à Educação Bilíngue, com a Libras como língua preferencial e o Português escrito como segunda língua. Uma forma de auxiliar os processos de ensino e aprendizagem é a utilização de jogos educativos, que muitas vezes não são acessiveis e desconsideram os objetivos de aprendizagem da Educação Bilíngue. Neste contexto, foi criada a metodologia CAJEDUS (CriAção de Jogos para a EDUcação de crianças Surdas) para apoiar o processo de concepção de jogos educativos para crianças Surdas de 4 e 5 anos com base nos objetivos da Educação Bilíngue. Foi conduzido um estudo de caso com desenvolvedores e seus resultados foram utilizados para aperfeiçoar a metodologia.

\section{Introdução}

A educação básica brasileira apresenta diversos desafios, destacando-se a necessidade de formular estratégias para assegurar que todas as crianças possam vivenciar um ensinoaprendizagem de qualidade. Com relação às crianças Surdas, é preciso respeitar seus direitos linguísticos, uma vez que sua comunicação preferencial e cultural é gestual-visual [Felipe 2006] e a Língua Portuguesa é de modalidade oral-auditiva.

Nesse sentido, instituições brasileiras especializadas no ensino de Surdos, como o INES (Instituto Nacional de Educação de Surdos), trabalham com a proposta metodológica de uma Educação Bilíngue [Felipe 2006]. Nessa proposta, a Libras (Língua Brasileira de Sinais) é utilizada/ensinada como sua primeira língua (L1) e o Português escrito como a segunda língua (L2), levando-se em conta que "as questões culturais históricas dessa minoria linguística também devem ser trabalhadas" [Felipe 2006]. 
A fim de apoiar os processos de ensino e aprendizagem, considera-se que jogos digitais possuem um grande potencial como ferramentas educacionais [Martins et al. 2019]. Considerando também a "importância do letramento para o desenvolvimento de habilidades cognitivas e sociais" [Aristizábal et al. 2017], partimos do pressuposto de que os jogos educativos podem auxiliar na aquisição de conhecimento por crianças Surdas, que poderão ajudar nesse processo de letramento.

Ainda que haja jogos de auxílio ao letramento das crianças Surdas [Khenissi et al. 2015], muitos ainda adotam o Português em elementos da interface, aumentando a dificuldade das crianças Surdas no processo de aprendizagem. Outro problema, central a esta pesquisa, é a não inclusão de educadores de Surdos ou de documentos pedagógicos especializados no processo de construção de jogos educativos de maneira a garantir que os conteúdos apresentados nos jogos sejam pertinentes aos objetivos de aprendizado das crianças nos perfis específicos endereçados.

Neste cenário, o presente trabalho apresenta a CAJEDUS, uma metodologia para a criação de jogos educativos para crianças Surdas de 4 e 5 anos, elaborada e testada com desenvolvedores de jogos que possuem pouca ou nenhuma experiência com o público infantil Surdo, levando-se em consideração os aspectos da Educação Infantil Bilíngue. A fim de avaliar a metodologia, foi realizado um estudo de caso, e seus resultados serviram de insumo ao aperfeiçoamento da metodologia CAJEDUS.

Portanto, este artigo apresentará essa pesquisa a partir dos seguintes tópicos: Fundamentação teórica para a construção da metodologia; Definição inicial da CAJEDUS; Estudo de caso realizado para avaliar a metodologia; Modificações realizadas após estudo de caso e, por último, as Considerações finais.

\section{Fundamentação Teórica}

Esta seção apresenta bases conceituais utilizadas na construção da metodologia: Design de jogos educativos e Documentos pedagógicos da Educação Infantil.

\subsection{Game Design de Jogos Educativos}

Jogos educativos têm por objetivo "divertir os alunos, aumentando a chance de aprenderem os conceitos, o conteúdo ou as habilidades embutidas no jogo" [Clua e Bittencourt 2004]. Além disso, são capazes de auxiliar o "desenvolvimento de conhecimento e habilidades cognitivas, propiciando uma compreensão mais profunda de princípios fundamentais de determinados assuntos" [Brom et al. 2011].

Uma etapa fundamental para a construção de jogos educativos é o game design, que "define a interação do jogador com o mundo do jogo, as ações que o jogador pode executar, a maneira como eles afetam o ambiente do jogo e como são apresentados ao jogador" [Schell 2019]. Assim, o game design define tanto o conteúdo didático do jogo quanto os elementos de jogo que farão o aluno motivado a jogar e a aprender.

Justamente pela sua importância e sua complexidade, é necessária uma equipe interdisciplinar para a construção de jogos educativos, que envolva simultaneamente especialistas de conhecimento técnico (ilustradores, programadores, entre outros) e o conhecimento pedagógico (professores, educadores, entre outros) [Perry et al. 2007]. Adicionalmente, os desenvolvedores devem levar em conta elementos de jogos e aspectos de acessibilidade de interfaces, seguindo o contexto, vivência e faixa etária das crianças. 
A partir da construção da metodologia juntamente com uma especialista da Educação Bilíngue de Surdos foram adotados bases pedagógicas oficiais da Educação Regular, que serão apresentadas nas próximas subseções. No entanto, estas bases não foram construídas a partir de uma perspectiva da Educação Bilíngue e, por isso, elas estão sendo complementadas por especialistas com o intuito de torná-las adequadas às crianças Surdas. Assim, a metodologia aqui apresentada inclui como insumo, além das bases oficiais, as primeiras contribuições de especialistas na Educação Bilíngue para crianças Surdas.

\subsection{Bases Pedagógicas da Educação Infantil}

Foram utilizadas 3 bases pedagógicas neste trabalho: as Diretrizes Nacionais para a Educação Infantil (DCNEI) [[Brasil e CNE 2010] a Base Nacional Comum Curricular (BNCC) [MEC 2017] - ambas bases da Educação Regular, e o Plano de curso de Libras anual da Educação Infantil - 4 e 5 anos [Cruz et al. 2015], da Educação Bilíngue.

As DCNEI visam "orientar as políticas públicas e a elaboração, planejamento, execução e avaliação de propostas pedagógicas e curriculares de Educação Infantil" [Brasil e CNE 2010]. Elas orientam o acesso das crianças ao conhecimento e às linguagens, além de garantir o direito à proteção, à saúde, à liberdade, à confiança, ao respeito, à dignidade, à brincadeira, à convivência e à interação com outras crianças.

Já a BNCC é um "documento de caráter normativo que define o conjunto de aprendizagens essenciais que todos os alunos devem desenvolver ao longo das etapas e modalidades da Educação Básica" [MEC 2017]. Especificamente para a Educação Infantil, as práticas e procedimentos que deverão ser adotados pelos professores são divididos em categorias intituladas campos de experiência e aprendizado.

Os campos de experiência e aprendizado são: 1. Espaços, tempos, quantidades, relações e transformações, que visa a promoção de experiências do mundo físico e sociocultural pelas crianças; 2 . Traços, sons, cores e formas, que visa o desenvolvimento crítico e estético das crianças; 3 . O eu, o outro e nós, que visa auxiliar a criança nas percepções sobre si mesma e sobre os outros; 4. Escuta, fala, pensamento e imaginação, que visa a participação das crianças na cultura oral e escrita; e 5. Corpo, gestos e movimentos, que visa a exploração e vivência de movimentos, gestos, olhares e sons pelas crianças.

Apesar de proporem o igual acesso ao Educação Regular de qualidade, tanto as DCNEI quanto a BNCC têm caráter genérico, não englobando as especificidades educacionais das crianças Surdas. Por isso, alunos de pós-graduação do INES, através da disciplina Educação Bilíngue para educandos Surdos, desenvolveram pesquisas para a complementação do documento específico da Educação Infantil Bilíngue. Dentre elas, a proposta para a criação do plano anual para crianças Surdas de 4 e 5 anos de Cruz et al. (2015), foi utilizada como base para esta pesquisa.

O plano anual proposto por Cruz et al. (2015) prevê um conjunto de objetivos de aprendizagem, conteúdos, procedimentos, recursos para cada área de conhecimento trabalhada nessa faixa etária, visando, principalmente, o desenvolvimento da Libras. Além da Libras, que é introduzida e trabalhada como L1, foi utilizada também a representação gráfica das línguas de sinais, conhecida como SignWriting ${ }^{1}$.

\footnotetext{
${ }^{1}$ Disponível em: http://www.signwriting.org/
} 
As áreas de conhecimento previstas por Cruz et al. (2015) foram: Libras e SignWriting como primeira língua e Português como segunda língua; Natureza e Sociedade; Matemática; e Educação Artística. Sumarizando, a partir da utilização dessas três documentações pedagógicas é possível desenvolver habilidades esperadas tanto pelo Ensino Infantil Regular quanto pelo Ensino Infantil Bilíngue, para crianças Surdas de 4 e 5 anos.

\section{Definição Inicial da CAJEDUS}

Com o objetivo de auxiliar a construção de jogos educativos para crianças Surdas de 4 e 5 anos, e visando o contexto da Educação Infantil Bilíngue, foi desenvolvida a metodologia CAJEDUS de design de jogos. A CAJEDUS visa o perfil de desenvolvedores de jogos com pouca ou nenhuma experiência com o público infantil Surdo, apoiando-os nos processos de conscientização e sensibilização.

A metodologia foi construída ancorada nas bases pedagógicas apresentadas na seção anterior, assim como no processo de game design. A CAJEDUS oferecia, em sua versão avaliada no estudo de caso, procedimentos para que desenvolvedores pudessem iniciar o desenvolvimento do projeto do jogo de forma prática e consciente, ilustrados na Figura 1, sendo eles: Diretrizes Gerais (DG); Diretrizes Específicas (DE); Game Design Document (GDD); e Prototipação. Eles serão abordados nas próximas subseções.

\section{Metodologia CAJEDUS}

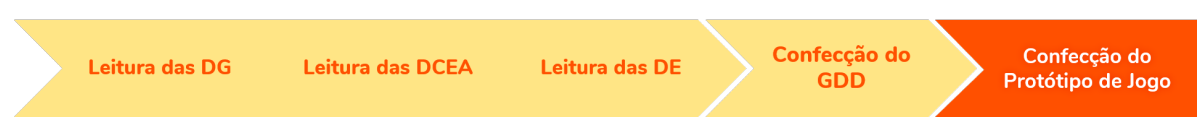

Figura 1. Definição Inicial da CAJEDUS.

\subsection{Diretrizes para Desenvolvimento de Jogos}

Para auxiliar no processo de entendimento do público-alvo, foram desenvolvidas diretrizes para o desenvolvimento de jogos, com base na leitura e na análise das DCNEI e da BNCC. Em seguida, foram criadas duas tabelas com diretrizes que consideravam aspectos educacionais no contexto de jogos educativos. Ambas as tabelas passaram por um processo de refinamento, a fim de encontrar redundâncias e melhorar suas descrições.

A primeira, Diretrizes Gerais (DG), continha boas práticas de aprendizagem, implementação, ética e acessibilidade. Essa tabela fornecia, para cada diretriz, seu indicador numérico, uma descrição mais detalhada da diretriz, um exemplo de um jogo que aplicava aquela diretriz e o seu tipo (implementação, ética ou acessibilidade). A outra, a das Diretrizes de Campos de Experiência e Aprendizado (DCEA), complementava as DG e visava orientar os desenvolvedores em relação aos campos de experiência e aprendizado escolhido para o jogo. Essa tabela continha as mesmas colunas da DG, se diferenciando apenas no tipo (campos de experiência e aprendizado da BNCC).

\subsection{Direcionamento Educacional}

O desenvolvimento do Direcionamento Educacional surgiu da necessidade de apresentar aos desenvolvedores conteúdos e objetivos da Educação Infantil Bilíngue que poderiam ser utilizados no jogo. Por mais que as DG oferecessem direcionamentos e boas práticas, 
IX Congresso Brasileiro de Informática na Educação (CBIE 2020)

Anais do XXXI Simpósio Brasileiro de Informática na Educação (SBIE 2020)

era necessário apresentar o contexto específico de aprendizado da criança Surda. Dessa forma, utilizou-se o trabalho de Cruz et al. (2015) como meio de integrar os desenvolvedores no contexto da Educação Infantil Bilíngue. A partir das 4 áreas de conhecimento apresentadas por Cruz et al. (2015), foram construídas 4 tabelas com seus respectivos objetivos de aprendizagem, conteúdos, procedimentos e recursos.

\subsection{Game Design Document}

O Game Design Document (GDD) é um documento utilizado para especificar as características do jogo, como suas mecânicas, personagens, fases, desafios, entre outras. Apesar de existirem modelos de GDDs disponíveis, poucos lidam com aspectos da Educação Infantil. A partir do framework de Canteri (2019) e seus 4 módulos (Ensino-Aprendizado, Gráficos e Interface, Jogabilidade e Tutoria e Aprendiz ou Jogador), foi elaborado um GDD que cobrisse aspectos educacionais da Educação Infantil Bilíngue e que fosse abrangente para trabalhar com gêneros complexos como RPG (Role Play Game) eletrônico.

No primeiro módulo do GDD, Ensino e Aprendizagem, os desenvolvedores deveriam apresentar os elementos educacionais e narrativos do jogo, ou seja, como e quais conteúdos seriam apresentados no jogo. No segundo módulo, Gráficos e Interface, deveriam se ater à caracterização do jogo, lidando com aspectos visuais do jogo, como personagens e itens. No terceiro módulo, Jogabilidade e Mecânicas, deveriam se preocupar como o fluxo do jogo é definido pelas mecânicas de jogo escolhidas. E, no quarto módulo, Aprendiz e Tutoria, deveriam refletir como oferecer suporte ao jogador de acordo com seu desempenho no jogo para que esse jogador alcance os objetivos pretendidos.

Dessa forma, utilização da metodologia CAJEDUS se dava da seguinte forma: Leitura das DG, das DCEA e do Direcionamento Educacional, sem ordem pré-definida, seguido pela confecção do GDD e a prototipação (de baixa, média ou alta fidelidade). A utilização da CAJEDUS será abordada na próxima seção.

\section{Avaliação da Metodologia}

A fim de avaliar a CAJEDUS com relação ao seu potencial de criação de jogos educativos adequados, foi realizado um estudo de caso, método de pesquisa que permite um conjunto menor de participantes e que tem um foco maior na análise qualitativa [Lazar et al. 2017]. O objetivo do estudo de caso era encontrar benefícios e problemas na CAJEDUS. Foram escolhidos 4 participantes dentro do público-alvo da CAJEDUS, ou seja, desenvolvedores de jogos com pouca ou nenhuma experiência com crianças Surdas.

A atividade proposta no estudo de caso consistiu na criação de um protótipo de jogo educativo RPG eletrônico para crianças Surdas de 4 e 5 anos. O gênero RPG eletrônico foi escolhido pela sua afinidade com os objetivos de aprendizagem da Educação Infantil Bilíngue. O cenário dado aos participantes foi construído baseado em uma demanda por parte do INES, para auxiliar no ensino da cultura indígena às crianças Surdas.

O experimento consistiu na leitura dos instrumentos da CAJEDUS e a realização de um brainstorming de ideias do jogo pelos participantes. A partir das ideias consolidadas, os participantes confeccionaram o GDD e o protótipo de baixa fidelidade no papel. Em seguida, os participantes preencheram um questionário pós estudo com o objetivo de capturar as impressões quanto à utilidade, à facilidade e à intenção de uso futuro da CA- 
JEDUS. Por último, eles participaram de uma entrevista em grupo, cujo objetivo era obter respostas em relação às suas impressões sobre a metodologia como um grupo ${ }^{2}$.

O jogo especificado pelos participantes foi um RPG eletrônico mobile, no qual uma criança Surda (personalizável) iria visitar uma tribo indígena para conhecer mais sobre sua cultura. O personagem deveria aprender habilidades cotidianas dos indígenas (caça, pesca, artesanato, entre outras), coletar itens e completar desafios, a fim de preencher um diário de viagem. A não escolha de um protagonista indígena foi justificada pelos desenvolvedores com a preocupação da ausência de local de fala indígena. A Figura 2 apresenta registros do experimento juntamente com o protótipo de jogo construído.

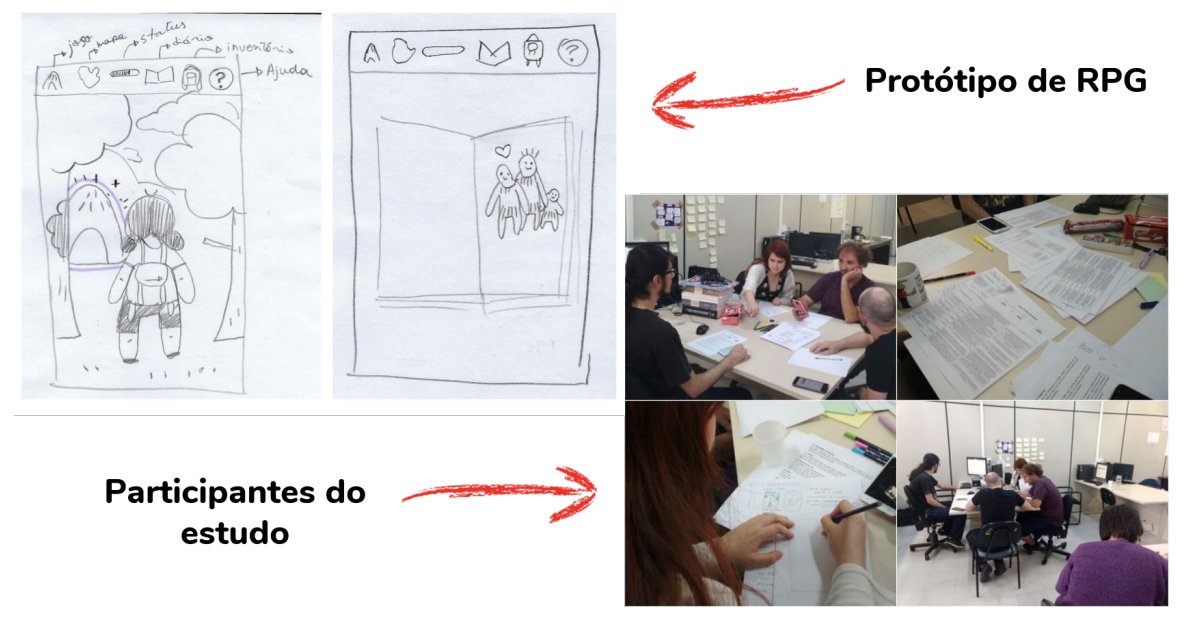

Figura 2. Protótipo produzido e registros dos participantes.

A partir da leitura e da análise do jogo, percebeu-se que faltou detalhamento em alguns pontos, apesar do fato de o material produzido pelos participantes cobrir o esperado de um GDD e protótipo funcionais. Ou seja, a partir do material confeccionado, era possível ter uma ideia geral do jogo e dar início ao seu desenvolvimento (artes, programação, roteirização, entre outros passos). Além disso, foi observado que o material produzido poderia ser refinado em iterações futuras pela equipe, utilizando a CAJEDUS.

Os dados obtidos foram analisados em duas etapas: uma análise quantitativa das questões múltipla escolha do questionário; e uma análise qualitativa dos dados textuais do estudo, das questões discursivas do questionário e da transcrição da entrevista. Em relação à análise quantitativa, ela mostrou que os participantes tiveram problemas para compreender a CAJEDUS, assim como que utilizá-la exigiu esforço mental significativo. Esse problema derivou-se da extensão e complexidade da versão da CAJEDUS avaliada, com muitas tabelas e textos extensos. Apesar disso, a metodologia auxiliou os desenvolvedores de jogos a construírem jogos educativos para crianças Surdas, além de lhes ensinar aspectos da cultura Surda e da Educação Infantil Bilíngue. Os participantes demonstraram interesse em utilizar a CAJEDUS em projetos futuros.

Em relação à análise qualitativa, a CAJEDUS foi classificada como possivelmente útil, abrangente (poderia ser utilizada para outros gêneros de jogos) e passível de aplicação em outros contextos (crianças em outros recortes). Apesar disso, a metodologia foi

\footnotetext{
${ }^{2}$ Link para acesso das perguntas do questionário e entrevista: https://bit. ly/2ZnQ21s
} 
considerada confusa e cansativa, pela falta de um roteiro claro, um documento especificando a ordem e a forma de utilização dos documentos. Os participantes sugeriram algumas formas de melhorar a visualização da metodologia, entre elas apresentá-la de uma forma mais dinâmica por meio de um jogo de cartas para a familiarização com as diretrizes, e a alteração da tabela para a posição vertical para facilitar sua leitura.

Pela entrevista, houve discussões sobre a importância de construir jogos de gêneros diferentes daqueles mais utilizados com crianças, como puzzle e aventura, já que isso determina outro papel de atuação, escolha e autonomia. Os participantes também afirmaram que a metodologia permitiu a compreensão das necessidades das crianças Surdas, quebrando estereótipos e preconceitos que eles tinham. Os participantes ainda afirmaram que a CAJEDUS não deve se limitar à bolha dos especialistas em desenvolvimento de jogos, mas também dar voz às crianças Surdas, a fim de oferecer protagonismo à criança na criação de tecnologias educacionais a ela direcionadas.

Em síntese, foi possível constatar que os participantes acharam a CAJEDUS útil para criar jogos para crianças Surdas, auxiliando-os na compreensão do gênero RPG eletrônico e dos conteúdos da Educação Infantil Bilíngue. O feedback e as sugestões obtidas foram adotadas e implementadas em uma nova versão da CAJEDUS, que será apresentada na próxima seção.

\section{CAJEDUS Pós Avaliação}

A partir do feedback dos participantes, confeccionou-se um manual de instruções para que os desenvolvedores pudessem ler antes de iniciar a produção do jogo. Essa demanda surgiu da necessidade apontada pelos participantes de se elaborar um roteiro contendo informações da metodologia e dos passos que deveriam ser seguidos para criar um jogo. Esse manual contém a motivação e os objetivos da CAJEDUS, assim como uma descrição das bases pedagógicas utilizadas, e uma explicação sobre os instrumentos da CAJEDUS juntamente com sua forma de utilização.

A disposição das tabelas de diretrizes foi modificada de horizontal para vertical para facilitar sua leitura. Além disso, foi adicionada no começo das tabelas uma descrição de como utilizá-las. A fonte das tabelas e seus elementos foram padronizados e as descrições das diretrizes foram simplificadas e resumidas.

Outra modificação realizada decorreu devido ao fato dos participantes não terem utilizado com frequência a tabela DCEA. A hipótese é que a utilização simultânea das áreas de conhecimento propostas por Cruz et al. (2015) e dos campos de experiência e aprendizado da BNCC sobrecarregaram cognitivamente os participantes. Dessa forma, o conteúdo da tabela de DCEA foi ajustado para utilizar apenas as áreas de conhecimento propostas por Cruz et al. (2015). Essa nova tabela foi intitulada "Diretrizes Específicas" (DE), e utilizada em conjunto com a área de conhecimento escolhida pelos desenvolvedores no Direcionamento Educacional. Essa atualização foi possível pois as áreas de conhecimento possuem conexões com os campos de experiência e aprendizado da BNCC.

Em relação ao Direcionamento Educacional, os participantes o julgaram confuso e com informações em excesso. Além disso, foi levantada a necessidade de apresentar as capacidades das crianças Surdas, para que ficasse claro o que poderia ser utilizado de mecânicas e léxico. Assim, o Direcionamento Educacional foi reestruturado num formato 
de 2 partes. Na primeira parte, foram apresentadas as capacidades das crianças Surdas e, na segunda parte, foram contemplados os objetivos de aprendizado e os conteúdos das quatro áreas de conhecimento propostas por Cruz et al. (2015), estruturadas em listas de verificação. Dessa forma, os desenvolvedores podem marcar os objetivos e conteúdos que tenham interesse em desenvolver.

Em relação ao GDD, flexibilizou-se sua estrutura, para que os desenvolvedores possam preenchê-lo na ordem desejada e pertinente para a equipe. Outro problema relatado foi que o GDD não oferecia espaço para desenhar ou escrever. Foram então adicionadas linhas e um quadro em tópicos do GDD que poderiam ter esboços de diagramas ou personagens. A fim de facilitar as discussões e diminuir a carga cognitiva dos desenvolvedores, foi adicionada, abaixo de cada tópico, uma nota que diz quais DGs podem auxiliar no ponto em questão. Portanto, sempre que os desenvolvedores estiverem em um tópico, eles poderão reler as DGs e discutir qual é a melhor forma de responder às questões levantadas pelo GDD. Por último, algumas definições do GDD foram aprofundadas, com o intuito de gerar mais discussões na equipe e respostas mais completas.

A prototipação também sofreu mudanças. Antes não tinha um procedimento definido nem direcionamento do que se deveria prototipar. Na nova versão do GDD foi determinada a inclusão de um campo de prototipação. Nesse campo, são apresentadas perguntas aos desenvolvedores para instigar discussões, além de sugestões de quais telas seriam importantes para uma visão inicial do jogo. Deixou-se claro quais DGs podem auxiliar no design das telas e também o fato de que os desenvolvedores são livres para utilizarem outras ferramentas de prototipação caso queiram.

Assim, em sua nova versão, ilustrada na Figura 3, a metodologia CAJEDUS ficou composta por 5 passos $^{3}$. O primeiro passo, a leitura das DGs, que consiste em: Leitura de todas as DGs atentamente; Destaque das DGs pertinentes ao projeto; Discussão em grupo das DGs prioritárias para o projeto; Consolidação de uma lista das DGs escolhidas pelo grupo. O resultado desse processo é uma lista consolidada de DGs.

\section{Metodologia CAJEDUS V2}

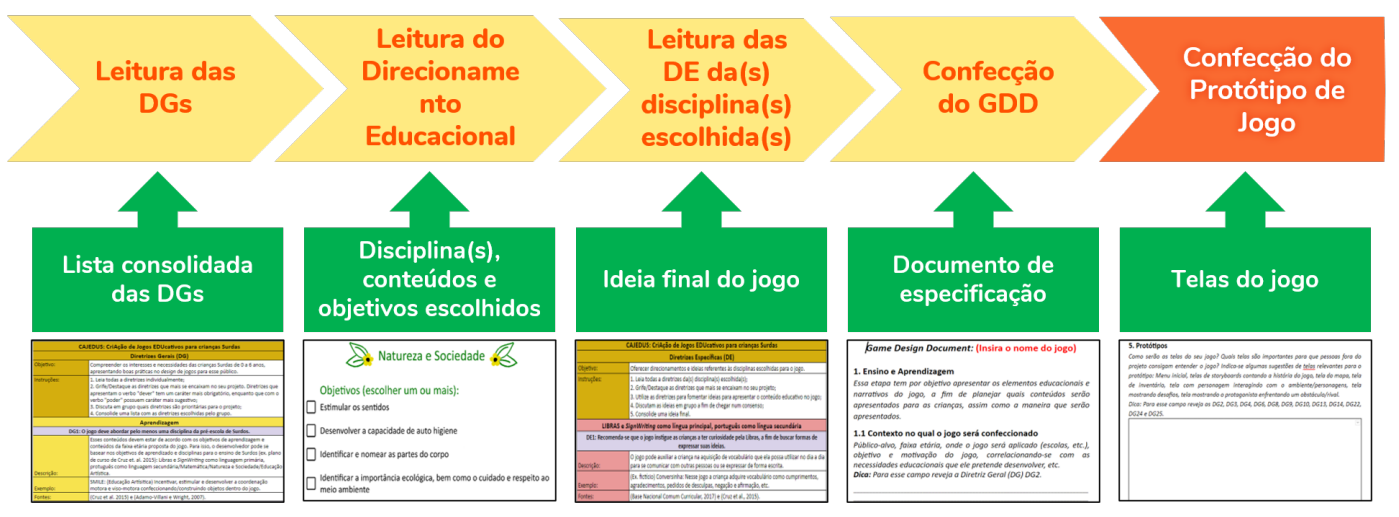

Figura 3. Passos da versão pós avaliação da CAJEDUS.

O segundo passo é a leitura do Direcionamento Educacional, que consiste em: Leitura da primeira parte do documento que envolve as especificações das capacidades

\footnotetext{
${ }^{3}$ Link para acesso para os materiais da CAJEDUS: https://bit . Iy/2Cjb4Fd
} 
das crianças Surdas de 4 e 5 anos, a fim de criar empatia com o público-alvo; Leitura da segunda parte do documento que envolve as áreas de conhecimento da Educação Infantil Bilíngue, escolhendo uma ou mais para o projeto; Leitura dos objetivos de aprendizagem e conteúdos das áreas de conhecimento escolhidas, marcando as que serão utilizadas no projeto. O resultado desse processo é uma lista com áreas de conhecimento, conteúdo(s) e objetivo(s) que serão utilizados no jogo.

O terceiro passo, leitura das DEs da(s) área(s) de conhecimento escolhida(s), consiste em: Leitura de todas as DE da(s) área(s) de conhecimento escolhida(s); Destaque as DE pertinentes ao projeto; Esboço de uma ideia de jogo em um papel a partir do material lido; Discussão em grupo das ideias formadas por cada membro; Consolidação em papel de uma ideia final de um jogo. O resultado desse processo é a ideia final do jogo.

O quarto passo, confecção do GDD a partir da ideia consolidada, consiste das seguintes atividades: Leitura dos tópicos do GDD; Discussão de quais elementos dos GDD são aplicáveis com a ideia do jogo; Preenchimento dos tópicos do GDD a partir do alinhamento de ideias dos membros do projeto; Revisão das DG e das DE para o preenchimento dos tópicos; Confecção de diagramas e esboços de elementos do jogo. $\mathrm{O}$ resultado desse processo é o GDD, um documento de especificação, completo e funcional, ou seja, com características bem definidas e passíveis de implementação.

O quinto passo, confecção do protótipo, consiste em: Definição de quais telas do jogo são mais importantes para a visualização da ideia geral proposta; Revisão das DG para a confecção das telas. A equipe pode escolher alguém para desenhar as telas ou utilizar técnicas de desenho em grupo, como braindrawing, podendo ser desenhado no espaço disponibilizado no GDD ou utilizando outras ferramentas. O resultado desse processo são telas do jogo, que devem oferecer uma visão geral da jogabilidade e interação.

\section{Considerações Finais}

A partir da metodologia CAJEDUS, espera-se que os desenvolvedores sejam capazes de criar jogos para crianças Surdas de 4 e 5 anos, considerando os aspectos da Educação Infantil Bilíngue. Como a CAJEDUS integra tanto conhecimentos do design de jogos como diretrizes para a Educação Infantil Regular e para a Educação Infantil Bilíngue, ela se caracteriza como uma proposta interdisciplinar, uma vez que propicia a integração de conhecimentos e, também, como uma proposta transdisciplinar por oportunizar a transcendência da subjetividade dos atores em relação ao seu conhecimento.

Por meio da análise dos resultados do estudo de caso, é possível afirmar que a CAJEDUS é potencialmente útil para desenvolver jogos, consegue comportar a utilização de diversos gêneros de jogos e leva em consideração uma abrangência de aspectos de aprendizagem, implementação e de acessibilidade para crianças Surdas. Além disso, a metodologia contribuiu para que os participantes se sensibilizassem em relação às necessidades e aos interesses do público-alvo. A partir das sugestões dos participantes foi possível atualizar a CAJEDUS em uma versão final mais robusta e prática. A CAJEDUS pode ser adaptada para outros recortes de faixa-etária e necessidades específicas.

A pesquisa desenvolvida possui como limitação a ausência de uma avaliação do material produzido pelos participantes do estudo de caso por professores da Educação Infantil Bilíngue, quanto à sua viabilidade de uso junto às crianças Surdas de 4 e 5 anos. Essa avaliação será realizada em trabalho futuro. 
Por último, pretende-se , na sequência, a criação de uma plataforma colaborativa de design de jogos que consiga ter como atores tanto os desenvolvedores quanto os professores da Educação Infantil Bilíngue e as crianças Surdas. Dessa forma, espera-se que os jogos produzidos a partir da união da visão técnica dos desenvolvedores, da visão pedagógica dos professores e do protagonismo de criança Surda, possam contribuir para uma educação de qualidade e motivadora.

\section{Agradecimentos}

Coordenação de Aperfeiçoamento de Pessoal de Nível Superior - Brasil (CAPES) - Código de Financiamento 001.

\section{Referências}

Aristizábal, L. F., Cano, S., e Collazos, C. (2017). Using storytelling to support the education of deaf children: A systematic literature review. Em International Conference of Design, User Experience, and Usability, pages 371-382. Springer.

Brasil, M. e CNE, C. (2010). Diretrizes curriculares nacionais para a educação infantil. Resolução CEB-CNE, (01).

Brom, C., Preuss, M., e Klement, D. (2011). Are educational computer micro-games engaging and effective for knowledge acquisition at high-schools? a quasi-experimental study. Computers \& Education, 57(3):1971-1988.

Canteri, R. d. P. (2019). JEIS - Framework Conceitual e Ferramenta de Autoria para a Construção de Jogos Digitais para Educação Infantil de Surdos. PhD thesis, Universidade Federal do Paraná.

Clua, E. W. G. e Bittencourt, J. R. (2004). Uma nova concepção para a criação de jogos educativos. Simpósio Brasileiro de Informática na Educação, 36.

Cruz, A. M., Miranda, J., Rossi, H., Maia, M. C., Mojon, Q. H., e Felipe, T. A. (2015). Plano anual para educação infantil bilíngue para crianças surdas - 4 e 5 anos. Curso de Especialização Educação Bilíngue. INES-DESU, Rio de Janeiro - RJ.

Felipe, T. A. (2006). Política públicas para inserção da Libras na educação de surdos. Revista Informativo-Científico Espaço. INES - Rio de Janeiro, (25/26):33-47.

Khenissi, M. A., Bouzid, Y., Essalmi, F., e Jemni, M. (2015). A learning game for deaf learners. Em 2015 IEEE 15th International Conference on Advanced Learning Technologies, pages 418-422. IEEE.

Lazar, J., Feng, J. H., e Hochheiser, H. (2017). Research methods in human-computer interaction. Morgan Kaufmann.

Martins, R. S., Raulino, F., Burlamaqui, A., e Burlamaqui, A. (2019). Sgddedu: A model of short game design document for digital educational games. International Journal for Innovation Education and Research, 7(2):167-180.

MEC, M. d. E. (2017). Base Nacional Comum Curricular: Educação é a base. MEC Brasília, DF. https://www.mec.gov.br/.

Perry, G. T., Timm, M. I., Silvestrim, F. G., e Schnaid, F. (2007). Necessidades específicas do design de jogos educacionais. SBGames 2007, pages 7-9.

Schell, J. (2019). The Art of Game Design: A book of lenses. AK Peters/CRC Press. 